
death separation constraints. We examined possible reasons for date discrepancies of

31 related individuals, such as dating of different skeletal elements or wiggles in the

\section{COMBINING ANCIENT DNA AND RADIOCARBON DATING DATA TO INCREASE CHRONOLOGICAL PRECISION}

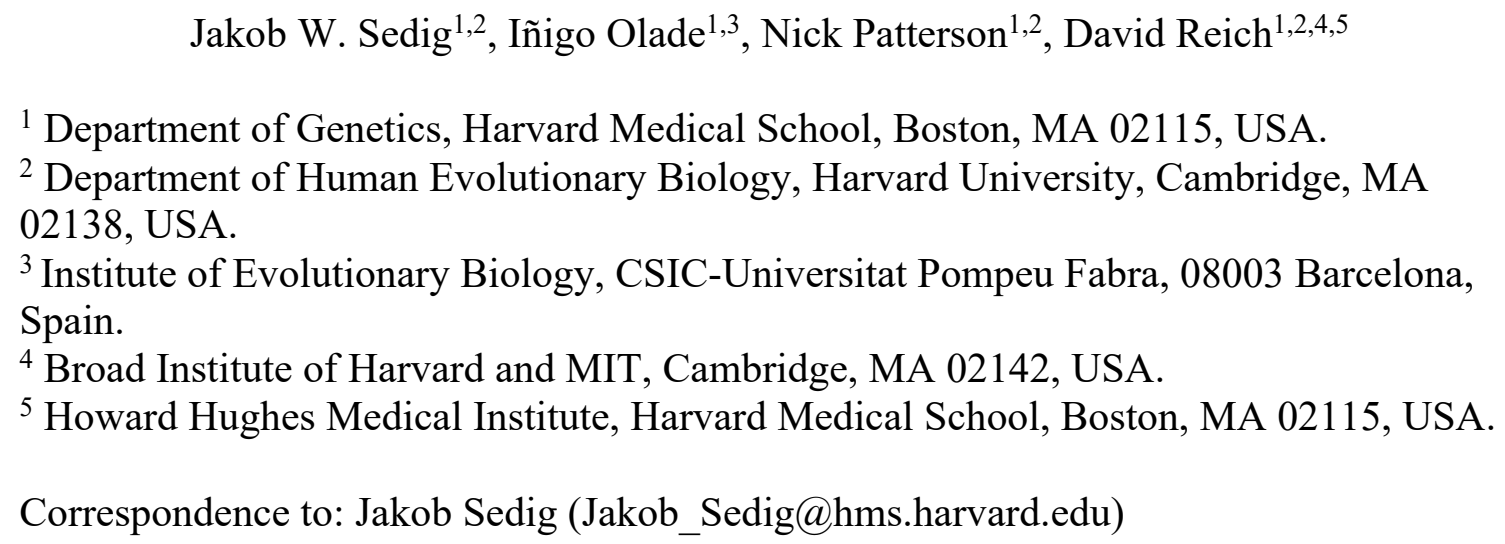

\section{Abstract}

This paper examines how ancient DNA data can enhance radiocarbon dating. Because

there is a limit to the number of years that can separate the dates of death of related

individuals, the ability to identify first-, second-, and third-degree relatives through

aDNA analysis can serve as a constraint on radiocarbon date range estimates. To

determine the number of years that can separate related individuals, we modeled

maximums derived from biological extremes of human reproduction and death ages and compiled data from historic and genealogical death records. We used these estimates to evaluate the date ranges of a global dataset of individuals that have been radiocarbon dated and for which ancient DNA analysis identified at least one relative. We found that many of these individuals could have their date ranges reduced by building in date of 
32 radiocarbon curve. Our research demonstrates that when combined, radiocarbon dating

33 and ancient DNA analysis can provide a refined and richer view of the past.

\section{Keywords}

36 Ancient DNA; radiocarbon dating; genealogy; Bayesian analysis

\section{1. Introduction}

41 This article examines how aDNA data can be used innovatively to help with a central

42 aspect of archaeological research — chronology. Ancient DNA (aDNA) data are

43 revolutionizing the field of archaeology. Within the last decade alone, aDNA analyses

44 have discovered new hominins (Reich et al., 2010), elucidated the spread of farming

45 through Europe (Lazaridis et al., 2016; Mathieson et al., 2015), shed light on the peopling

46 of the Americas and Oceania (Lipson et al., 2018; Moreno-Mayar et al., 2018; Posth et

47 al., 2018; Rasmussen et al., 2014; Skoglund et al., 2016), and more. While aDNA has

48 helped provide insight on long-standing archaeological questions, exponentially

49 increasing aDNA data has created unique opportunities for the examination of finer-

50 grained issues, and even archaeological methods.

51 The basis of the work presented here is tied to the fact that there is a maximum

52 number of years that can separate the dates of death (DOD) for two or more genetically

53 related individuals. For example, it is exceedingly rare for a mother to die 100 years

54 before her daughter, particularly in pre-modern societies. Thus, if two or more 
55 individuals are identified as biological relatives through aDNA analysis and those

56 individuals are radiocarbon dated, their relatedness can be used as a prior or constraint

57 when analyzing their overlapping radiocarbon date ranges. Using these constraints, we

58 examine how the identification of genetic relatives can help identify errors and outliers in

59 radiocarbon dating, how biological relatedness can be used to constrain overlapping

60 radiocarbon date ranges and increase dating precision, and how application of the

61 methods to a large database of published ancient DNA data

62 (https://reich.hms.harvard.edu/downloadable-genotypes-present-day-and-ancient-dna-

63 data-compiled-published-papers) can reveal potential larger issues in the radiocarbon

64 record at particular times and places.

65

66

\section{2. Materials and Methods}

2.1 Identification of genetic relatives with ancient DNA

70 Identification of genetic relatives has become standard practice in ancient DNA analysis.

71 Typically, individuals which are screened and produce working genomic data are

72 compared against each other and previously analyzed individuals from similar geographic

73 regions and time periods to identify unique genetic relationships. For each pair of

74 individuals in this study, we computed the mean mismatch rate using all the autosomal

75 SNPs with at least one sequencing read for both individuals in the comparison (this

76 procedure to identify genetic relatives is described in Kennett et al. (2017:156) and van

77 de Loosdrecht et al. (2018:15), and is similar to that in Kuhn et al. (2018:157)). In the 
78 cases with more than one sequencing read at a particular SNP for a given individual, we

79 randomly sample one for analysis. We then estimate relatedness coefficients as in

80 Kennett et al $(2017: 156): \mathrm{r}=1-((\mathrm{x}-\mathrm{b}) / \mathrm{b})$ with $\mathrm{x}$ being the mismatch rate and $\mathrm{b}$ the base

81 mismatch rate expected for two genetically identical individuals from that populations,

82 which we estimate by computing intra-individual mismatch-rates. We also compute $95 \%$

83 confidence intervals using block jackknife standard errors (Olalde et al., 2019:S61).

84 While such analysis can detect relationships up to the 5th degree, we limit relationships

85 here to 3rd degree maximum, as DOD date separations become too great to be of use

86 with decreasing genetic relatedness (e.g. great-grandparents and grandchildren).

882.2 Genetic relatives and DOD separation maximums

90 Below, two approaches — biological maximums and genealogically and historically

91 derived estimates - are examined for determining the DOD separation of genetically

92 related individuals. The biological maximums serve as theoretical extremes that, while

93 biologically possible, are very rare and unlikely to occur, especially in pre-industrial

94 archaeological cultures. Genealogically and historically $(\mathrm{GH})$ derived DOD separations

95 were created through the examination of genealogical records and historic data and

96 reflect more realistic estimates of the number of years between the death of two related

97 individuals.

98 
101 Biological maximum estimates use extremes of human reproduction and lifespan to

102 produce maximum DOD separation estimates. Figures 1 and 2 (also see SM 1) are

103 diagrams of how these estimates were modeled. The start of these models is set at $0 \mathrm{CE}$.

104 At this point, a couple consisting of a 15-year-old male and female parent a male child.

105 This child dies at birth, but both parents live to be 100 years old. Thus, the DOD

106 separation between the child and parents would be 85 years. If instead the mother died

107 during childbirth, but the child lived to 100 years old, the maximum DOD separation

108 between parents-offspring would be 100 years. Siblings have an even greater potential

109 maximum DOD separation, as Figure 2 demonstrates. In this model, the 15-year-old

110 couple has a male child that dies at $0 \mathrm{CE}$. That same couple has another child 30 years

111 later (when they are 45 years old); that second child then dies 100 years later. So, the

112 maximum separation between the siblings is 130 years.

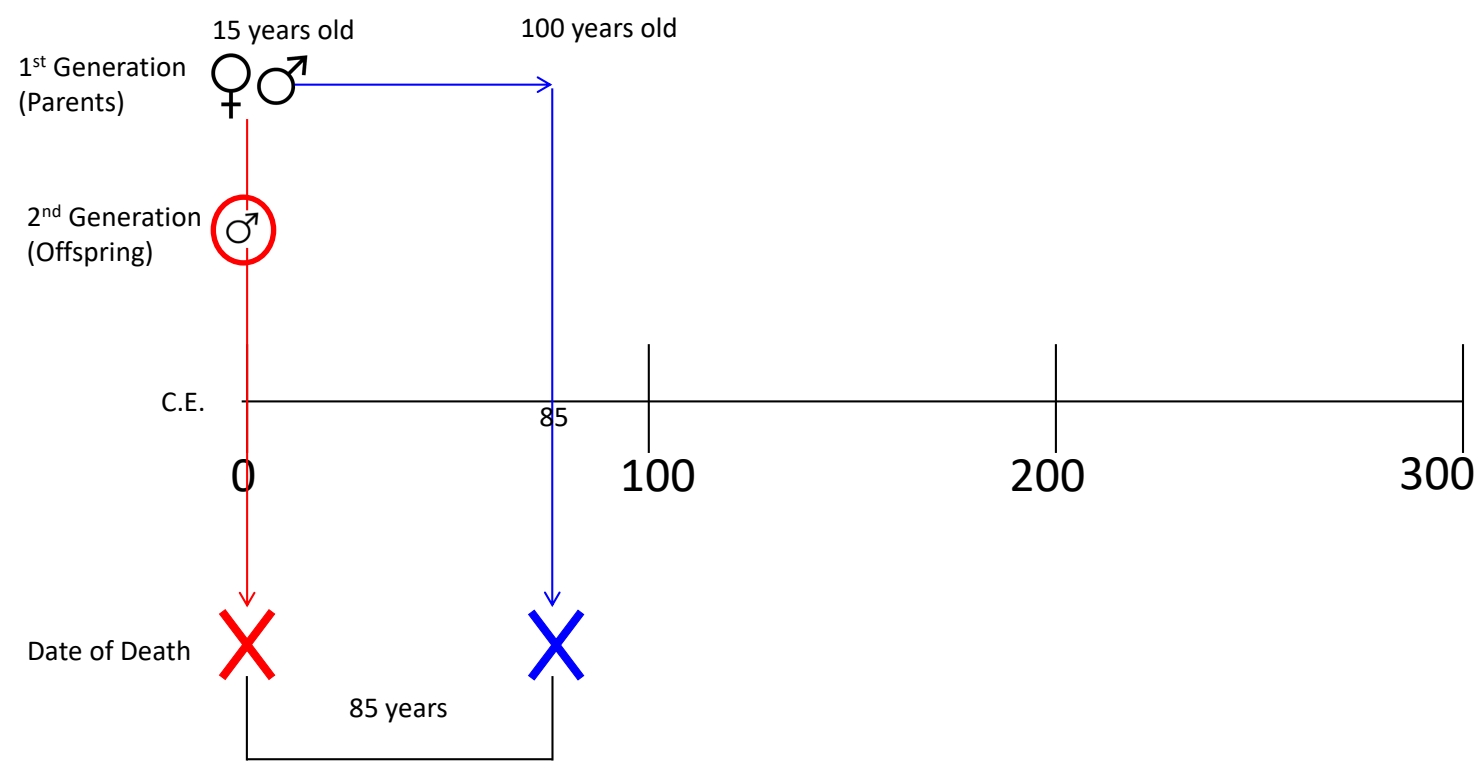

113

114 Figure 1. Model of biological maximum date of death separation for parents-offspring. 


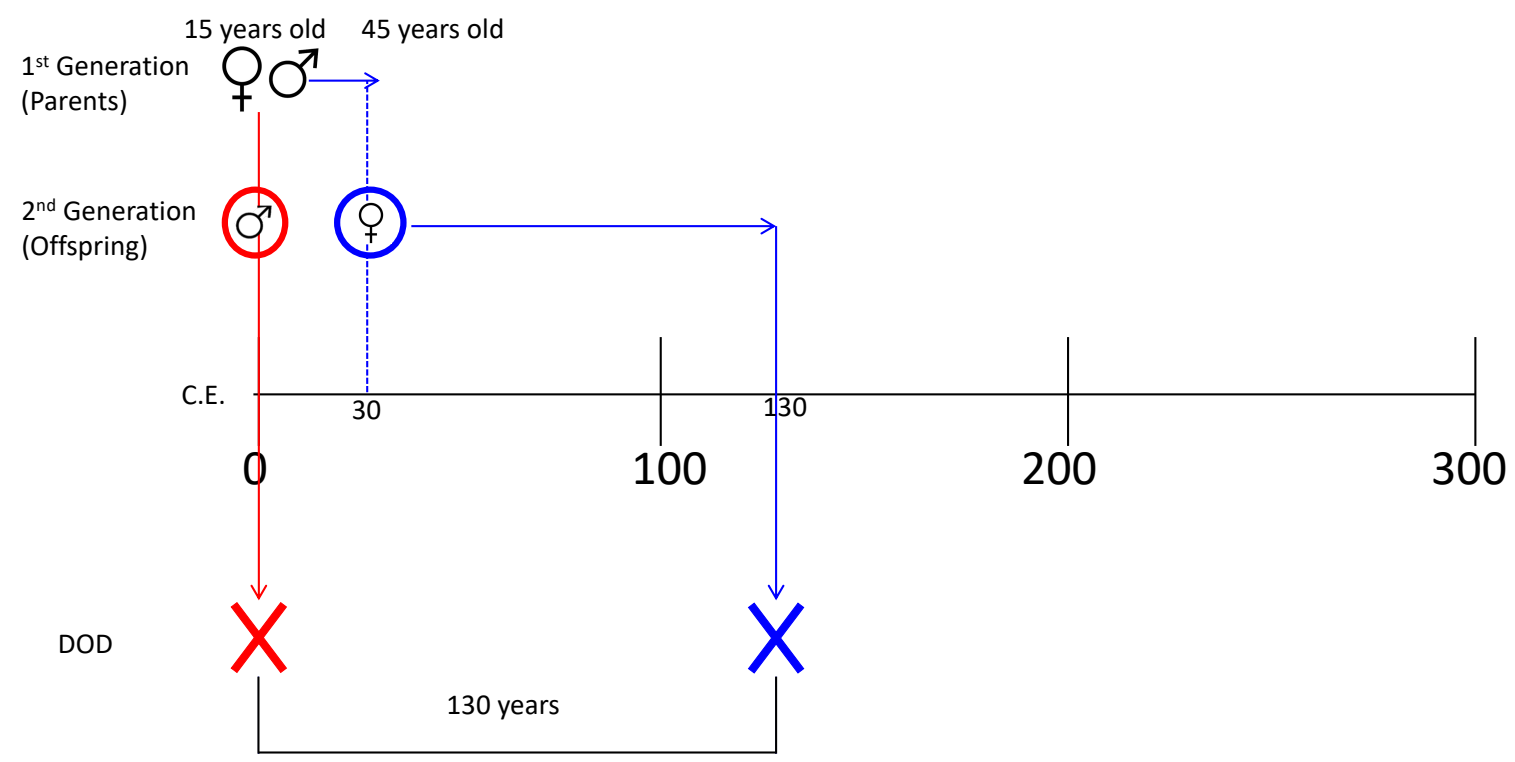

116 Figure 2. Model of biological maximum date of death separation for siblings.

118 Using these parameters, a number of potential biological maximums were

119 modeled for various degrees of genetic relatedness (Table 1; see SM 1 for diagrams of

120 models). The biological DOD maximums presented above and in Table 1 are reliant on

121 extremes - producing children at the biologically earliest and latest possible ages and

122 living to extreme old age. While possible, these DOD separations are not realistic, and

123 are largely ineffective as constraints on $\mathrm{C} 14$ date range distributions. Thus, to more

124 effectively examine how date of death separations for related individuals can be applied

125 to overlapping radiocarbon ranges, we also compiled birth and death data from historical

126 and genealogical records. 
131 Table 1. Theoretical DOD separation biological maximums.

\begin{tabular}{ll} 
Relation & $\begin{array}{l}\text { Max Years } \\
\text { Separation }\end{array}$ \\
\hline $1^{\text {st }}$ (Parents-Offspring) & 100 \\
\hline $1^{\text {st }}$ (Siblings) & 135 \\
\hline $\begin{array}{l}2^{\text {nd }} \text { (Grandparents- } \\
\text { Grandchildren })\end{array}$ & 180 \\
\hline $3^{\text {rd }}$ (Cousins) & 195 \\
\hline $2^{\text {nd }}$ (Aunts/Uncles- \\
Nieces/Nephews $)$ & 210
\end{tabular}

1332.4 Genealogically and Historically Derived DOD Estimates

135 We began compiling data on the date of death separations for related individuals

136 by consulting the plethora of genealogical and historical data that are publicly available

137 online. Many of these databases consist primarily of people of European ancestry who

138 lived within the last two centuries. However, to create date of death estimates from

139 heterogenous data, we sought non-European focused databases for relatives' death dates.

140 Data were gathered from historic Anglo cemeteries, and online databases of birth and

141 death dates for Cherokee, Tlingit, and other Native American groups (SM 2). Data were

142 sorted by categories of relatedness: parent-offspring, sibling, grandparent-grandchild, and

143 other $2^{\text {nd }}-3^{\text {rd }}$ degree (aunts-uncles/nieces-nephews and cousins).

144 The DOD separation for related individuals was compiled into a spreadsheet for

145 each genealogical database (SM 2). DOD separations were calculated by identifying

146 related individuals then subtracting the dates of death (i.e. if a mother and daughter were

147 identified, and the mother died in $1800 \mathrm{CE}$ and the daughter $1850 \mathrm{CE}$, the separation 
148 between the two entered in the database would be 50). For parent-child and grandparent-

149 grandchild relationships the signed value of the DOD was recorded. As will be discussed

150 later, knowing whether the child died before the parent (which would result in a negative

151 value) is useful for building constraints of parent-child and grandparent-grandchild

152 radiocarbon ranges. However, since in many instances aDNA cannot determine the

153 relatedness direction of two individuals (e.g. which is the mother and which is the

154 daughter) the absolute value of DOD separation of each relative pair was recorded for

155 each relationship type and is primarily used for the analyses below.

156 A total of 5235 relative DOD separations were recorded: 800 parent-offspring,

157813 sibling, 485 grandparent-grandchild, and 3137 other $2^{\text {nd }-} 3^{\text {rd }}$ degree. The means,

158 medians, and standard deviations of the absolute value for each relationship type were

159 then calculated; the results are provided in Table 2 (see also SM 2).

160

161 Table 2. Compiled genealogical and historical data for DOD absolute value separation

\begin{tabular}{lllll} 
& $\begin{array}{l}\text { Parent- } \\
\text { Offspring }\end{array}$ & Sibling & $\begin{array}{l}\text { Grandparent- } \\
\text { Grandchild }\end{array}$ & $\begin{array}{l}\text { Other } \mathbf{2}^{\text {nd }}-3^{\text {rd }} \\
\text { relationships }\end{array}$ \\
\hline Mean & 28.84 & 26.33 & 35.00 & 34.94 \\
\hline Median & 26 & 20 & 39 & 30 \\
\hline Standard Dev. & 18.94 & 22.41 & 31.93 & 25.6
\end{tabular}

164 The data in Table 2 demonstrate that the biologically maximum DOD separation

165 estimates in Table 1 are truly extremes. The largest mean separation in the GH dataset

166 was 35.00 years between grandparents-grandchildren. The single greatest DOD

167 separation in all the data was 117 years between Cherokee $2^{\text {nd }} / 3^{\text {rd }}$ degree relatives - still 
16893 years short of the $2^{\text {nd }} / 3^{\text {rd }}$ degree maximum theoretical estimate ( 210 years). The mean

169 GH DOD separation estimates for parents-offspring, siblings, and grandparents-

170 grandchildren are $71.16,108.67$, and 145.00 less than the biological maximum separation

171 estimates (Table 1), respectively.

172 The DOD separations above were produced by manual collection from online,

173 publicly available resources. However, in a 2018 study Kaplanis and colleagues

174 developed software and an analysis pipeline to examine genealogies of millions of

175 individuals downloaded from the online genealogical database geni.com. Kaplanis et al.

176 (2018) used this data to construct family trees (sometimes containing millions of

177 individuals); the anonymized data from this study were made available to download

178 (https://familinx.org/). Significantly, the data contained information on which individuals

179 had parent-offspring relationships, and the death date for each individual. We therefore

180 downloaded these data and found the DOD separation for over 8 million parents and

181 offspring (SM 3). We removed pairs with data errors (for example a death date of 3500)

182 and used the biological DOD separations defined above for parent-offspring as

183 constraints (i.e. 85 years for children dying before parents and 100 years for parents

184 dying before children). The mean absolute value DOD separation for these 8 million

185 parent-offspring pairs was 31.43 years, slightly higher than the mean value we manually

186 collected (28.84; SM 2); however, this should be expected as the geni.com data is heavily

187 weighted toward modern, European individuals who likely had longer life spans. Overall, 188 the similarity between the Kaplanis et al. 2018 data and the genealogical and historical

189 data we manually curated demonstrates that the DOD separations we obtained represent

190 more realistic DOD separations for related individuals than the biological maximums. 
Although the DOD separation estimates derived from GH data are more reflective

192 of separations between genetic relatives than the biologically possible maximums, the

$193 \mathrm{GH}$ data presented here should be viewed only as rough estimates. More precise

194 estimates could be tailored for particular types of social organization, such as hunter-

195 gatherers, pastoralists, agriculturalists, city-dwellers, nomads, etc. However, should

196 researchers wish to create new models, the GH estimates above likely will not be

197 exceeded, as many of the separations were derived from individuals who lived after the

198 industrial revolution and likely had longer lifespans than ancient individuals.

\section{3. Application and analysis}

2023.1 Applications of relatedness data to radiocarbon dated individuals

204 We examined the ancient DNA database of published individuals from geographic

205 locales across the globe spanning more than 30,000 years (although there is bias towards

206 the last 10000 years in western Eurasia; see Marciniak and Perry, 2017; Reich, 2018) to

207 test how DOD separation estimates can be applied to related individuals and examine if

208 any new insights can be revealed. As of May 2020, 3,965 published individuals were in

209 the database, with 1,127 ancient individuals having at least one identified relative. Of

210 those, 190 pairs (231 unique individuals, SM 4) had both individuals C14 dated (all dates

211 generated with AMS and calibrated two-sigma), allowing for analysis of DOD

212 separations and constraints. 


\subsection{Outlier identification}

216 The most basic example of how genetic relatedness can help refine radiocarbon dating is

217 through the identification of anomalies. Archaeologists have long recognized that C14

218 sample contamination can occur and that other issues, such as the marine reservoir effect,

219 can cause dates to be skewed (Taylor and Bar-Yosef, 2014). Genetic relatedness is a new

220 independent measurement that can be used to test the validity of radiocarbon date ranges,

221 particularly for samples that might not be obvious outliers. For example, if five skeletons

222 from the same stratigraphic layer in a cemetery were dated, and four of those individuals

223 had calibrated ranges of approximately CE 1-500, while one had a calibrated date range

224 of approximately $2500-2000 \mathrm{BCE}$, that one sample would seem suspicious and would

225 likely be redated (Figure 3). However, if that outlier instead had a range of approximately

226 CE 600-1000, the skeleton might not be redated, as it is relatively close to the range of

227 the other four skeletons (Figure 3). But, if it was determined that the outlier was actually

228 the father of skeleton 3 , then it would be highly suspicious that skeleton 5 could be older

229 than skeleton 3, as the DOD separation between father and offspring cannot biologically

230 be more than 100 years, and more realistically is around 29 years from GH DOD

231 estimates (Table 1). Such an example was discovered in the database.
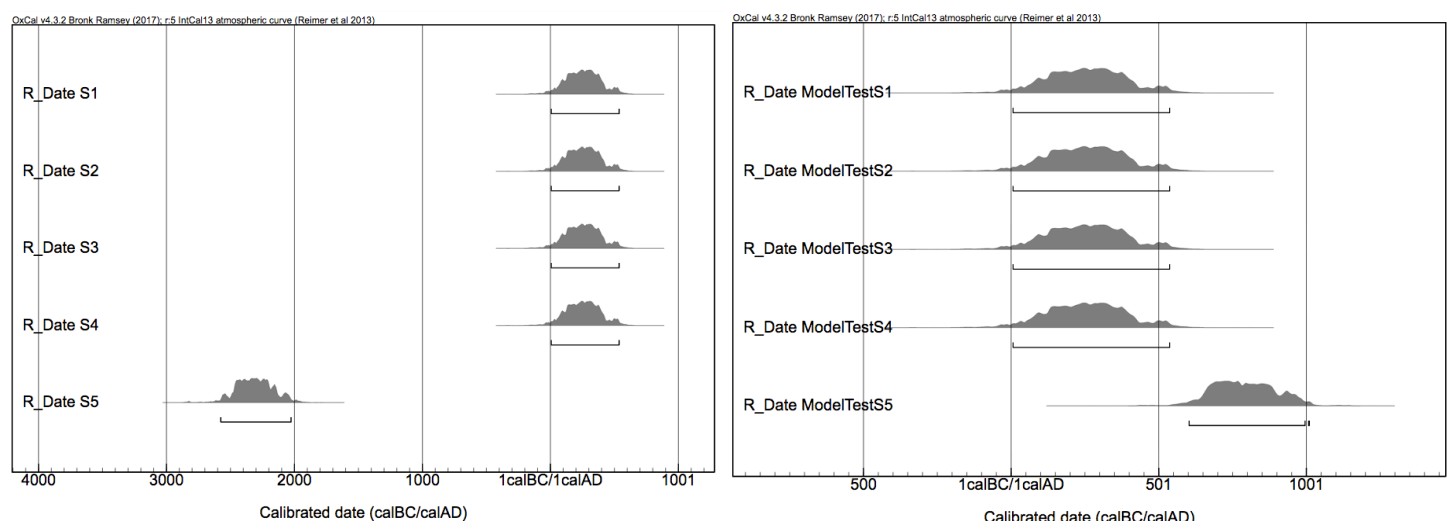
233 Figure 3. Examples of clear outliers in radiocarbon dating (L) and an individual that is an 234 outlier but does have overlap with other dates $(\mathrm{R})$.

236 Two individuals, I2457 and I2600 (Olalde et al., 2018), were excavated from two

237 sites, Amesbury Down and Porton Down, Britain, separated by approximately $5 \mathrm{~km}$. The

238 samples had been previously radiocarbon dated; prior to aDNA analysis and the dates did

239 not seem suspect $($ I $2457=3890+30 ; 2480-2280$ calBCE, SUERC-36210;

240 I2600=3646 $\pm 27 ; 2140-1940$ calBCE, SUERC-43374; Figure 4). Ancient DNA analysis

241 of the samples revealed that I2600 was the daughter of I2457, but there was thus no

242 overlap in the calibrated distributions of the father-daughter pair. The minimum DOD

243 separation between the father and daughter was 140 years, which exceeds even maximum

244 biological estimates. Individual I2457 (the father) was therefore redated and the new date

245 (3717 $\pm 28 ; 2200-2031$ calBCE; SUERC-69975) fit within the expected DOD spread

246 (Figure 5).

247

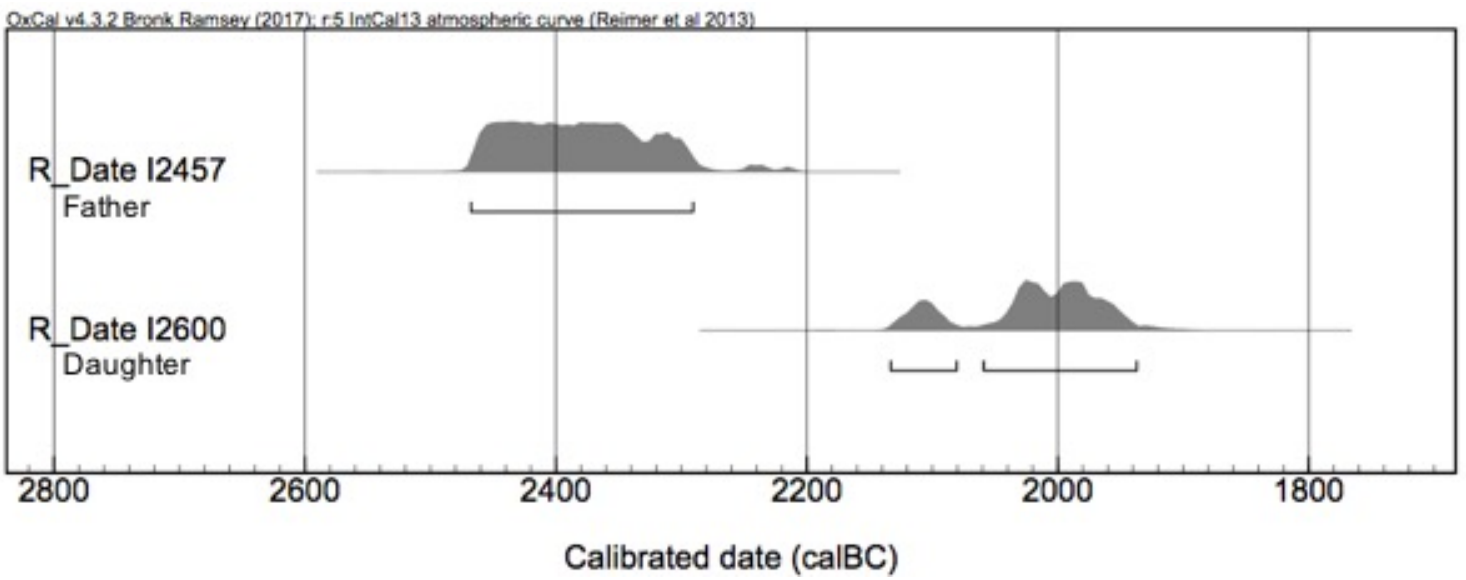

249 Figure 4. Original AMS dates for I2457 and I1600. 


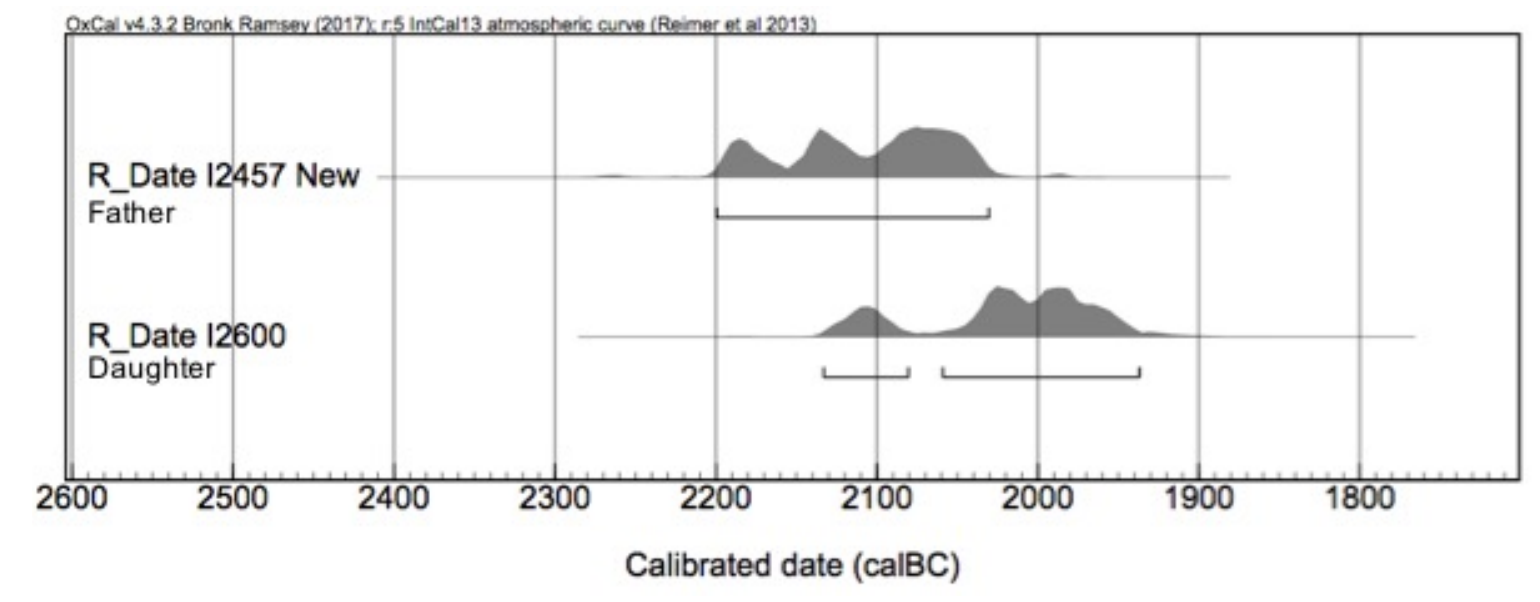

Figure 5. New AMS date for I2457.

\section{$255 \quad 3.3$ Range tightening of radiocarbon date distributions}

257 Along with detecting outliers, we examined the potential of using DOD separations to 258 refine calibrated date ranges in instances where two (or more) related individuals with 259 overlapping C14 date probability distribution ranges are identified. Using biological 260 maximums as an example, consider a father whose AMS range is 1-500 calCE and a

261 daughter whose range is 400-1000 calCE. Since the father cannot have died more than

262100 years before or after the daughter, the father's range can be constrained to

263 approximately 300-500 CE; since the daughter cannot have died more than 100 years

264 after the father, the daughter's range can be constrained to 400-600 CE.

265 While informative for some related pairs, the maximum biological separation

266 estimate is often too large and not applicable to most related and dated individuals in the

267 dataset. Individuals I2457 and I2600 serve as examples of how GH DOD separations can

268 be used as constraints for the date ranges of related individuals. Using the new date for

269 I2457 and building in the 29-year parent-offspring GH DOD constraint allows the 
270 individual and combined date ranges to be reduced (Figure 6). With this estimate, the tail 271 ends of the calibrated distributions for I2457 and I2600 should not be separated by more 272 than 29 years. In other words, since I2457 likely died an average of 29 years before

273 I2600, adding 29 years to the left end of the two-sigma calibrated date range for I2600, 2742134 BCE, creates a constraint for the earliest date of I2457 at 2163 BCE. On the other 275 end of the distributions, since I2600 likely did not die more than 29 years after I2457, 276 adding 29 years to the latest dates of the 2-sigma calibrated range of I2457, $2031 \mathrm{BCE}$, 277 creates a constraint for the latest date of I2600 at 2002 BCE (Figure 6).

278

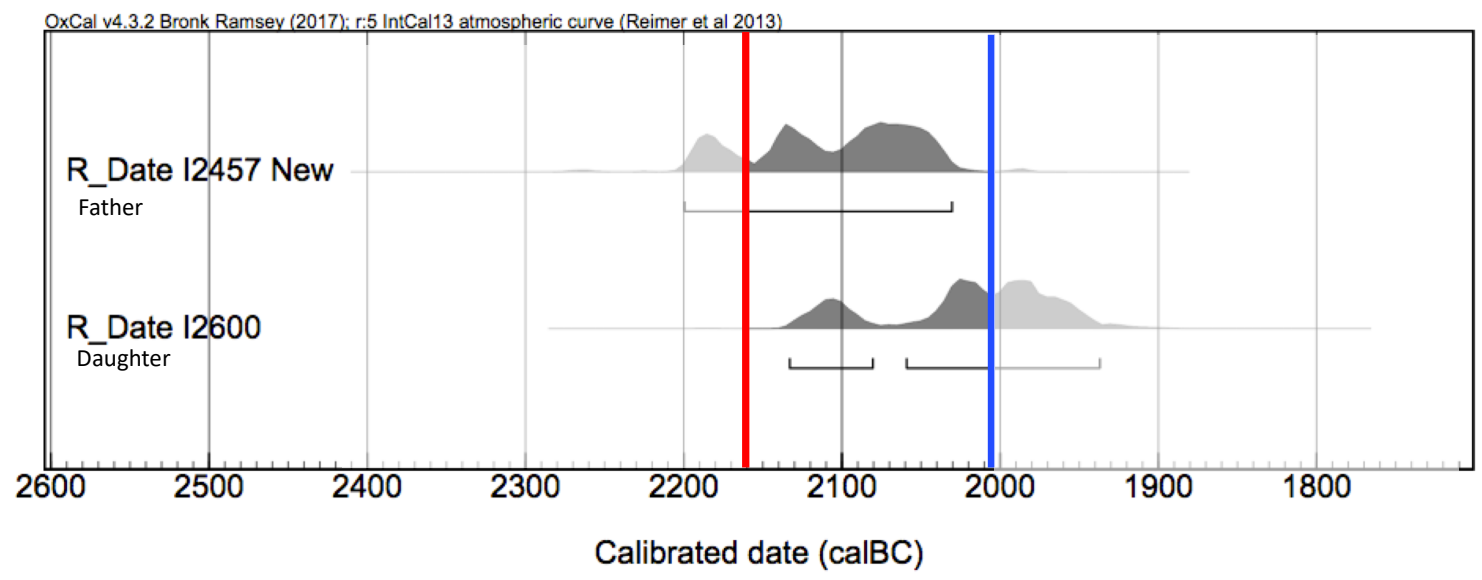

I2457 Original 2-sigma range: 2200-2031 BCE (3717+28 BP) Constrained Range: 2162-2031 BCE I2600 Original 2-sigma range: 2134-1938 BCE (3646_27 BP) Constrained Range: 2134-2003 BCE

280 Figure 6. AMS ranges for I2457 and I2600 with relative constraints added.

281

282 Not all date ranges can be constrained as significantly as with these relatives, as

283 demonstrated by individuals I1054 and I1053 (Narasimhan et al., 2019), two siblings

284 from the Russian Sintashta archaeological culture. Their date ranges overlap almost

285 entirely (Figure 7). Thus, using the 26-year GH DOD separation estimate for siblings, 

ranges (a change in only two years).

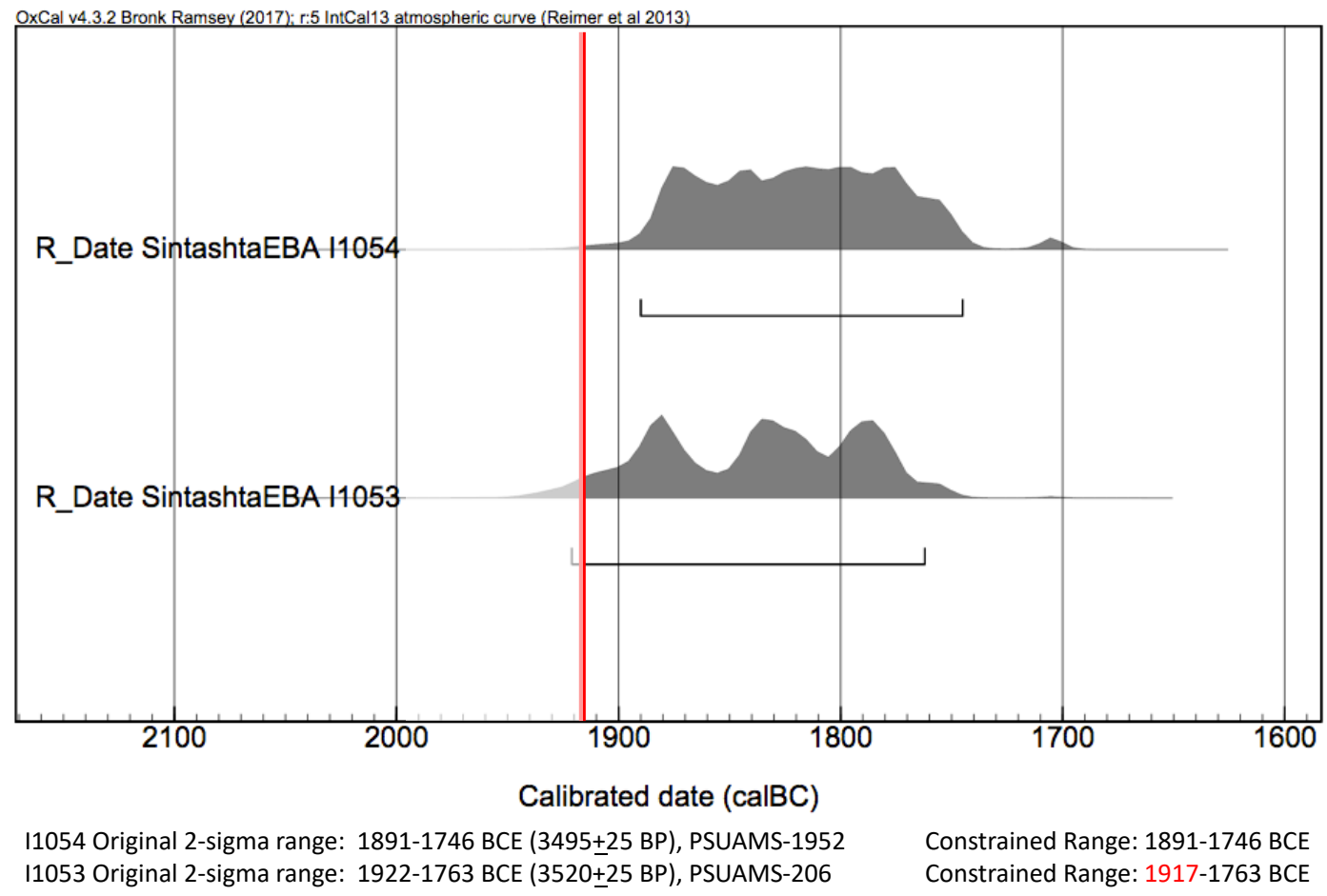

289 Figure 7. AMS ranges for I1054 and I1053 with relative constraints added.

\subsection{Constraints applied to database}

293 We applied the date range distribution tail trimming approach outlined above to the 190

294 dated relative pairs in the database (we used separations of 29 years for parent-offspring,

29526 for siblings, and 35 years for 2nd-3rd degree of unknown specificity as constraints).

296 We focus below on GH DOD derived constraints, as the biologically maximal DOD

297 constraints often exceeded the overlap of the related pairs' C14 distributions. As

298 mentioned above, since the type and directionality of relationships often cannot be

299 precisely determined through aDNA analysis, we used the largest mean absolute values 
300 for DOD separations derived from GH data. In other words, if a pair could only be

301 distinguished as 1 st degree relatives (either parent-offspring or siblings), the largest mean

302 GH DOD separation for first degree relatives was used, which is 29 years (for parent-

303 offspring, not 26 years for siblings).

304 After applying GH DOD constraints to the dataset, we removed 21 pairs because

305 their 2-sigma calibrated date ranges did not overlap and exceeded the GH DOD

306 estimates, suggesting dating error/a need for redating (uncorrected marine reservoir

307 effect, sample contamination, etc). This left a total of 169 pairs and 219 unique

308 individuals (SM 4). Applying the GH constraints, we were able to reduce the 2-sigma

309 calibrated ranges of 132 individuals, with a mean reduction of 54.47 years (Table 3 and

310 SM 4.2); 77 individuals had even more of a reduction than this. Figure 8 is a graph of the

311 difference between the original 2-sigma calibrated range and the GH constrained range

312 for each individual.

313

314 Table 3. Date ranges for all individuals in relative pairs.

\begin{tabular}{llll} 
& $\begin{array}{l}\text { Original } \\
\text { Range }^{1}\end{array}$ & $\begin{array}{l}\text { GH } \\
\text { Range }^{2}\end{array}$ & $\begin{array}{l}\text { (O)- } \\
(\mathbf{G H}) \\
\text { Change }^{3}\end{array}$ \\
\hline Mean & 203.44 & 149.00 & 54.47 \\
\hline $\begin{array}{l}\text { Standard } \\
\text { Deviation }\end{array}$ & 95.89 & 86.60 & 75.82 \\
\hline
\end{tabular}

315 'Original range is the 2-sigma calibrated range for the individual. ${ }^{2} \mathrm{GH}$ range builds in the 316 constraints derived from ethnographic/historic records for each individual (Table 2).

$313^{3}(\mathrm{O})-(\mathrm{GH})$ Change is the original range minus the constrained biological range for each 318 individual, which reveals how many years of the original range are removed from the tail 319 ends of the 2-sigma distributions when GH estimate constraints are applied. 


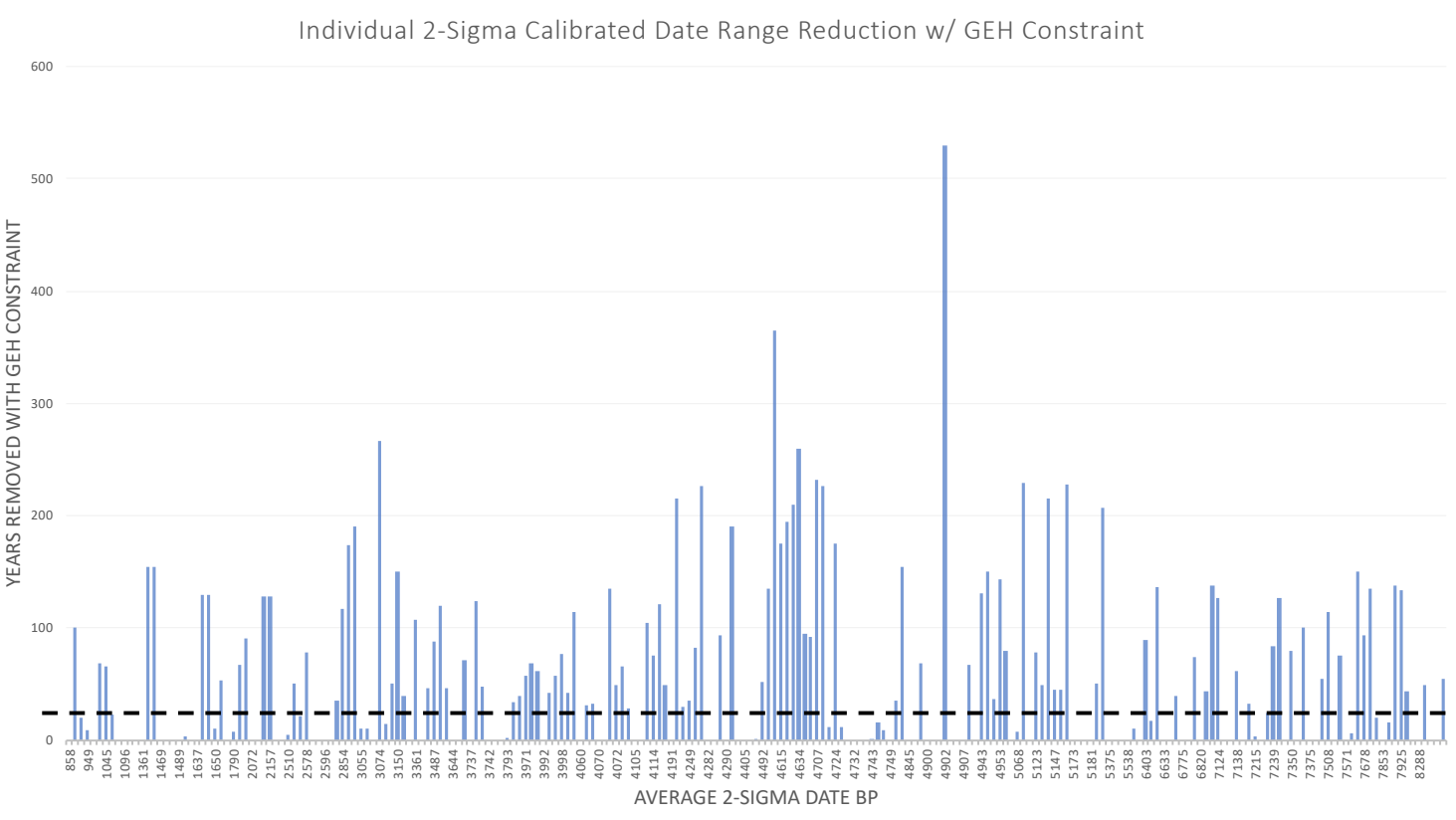

321 Figure 8. Difference between original 2 sigma calibrated date range and GH constrained 322 range for all 219 individuals, ordered from most recent date BP to oldest.

325 elements were radiocarbon dated for each individual in the relative pairs. Studies have

326 demonstrated that different skeletal elements have different rates of remodeling and

327 carbon uptake (Calcagnile et al., 2013; Cook et al., 2015; Hansen et al., 2017; Pinhasi et

328 al., 2015); for example, a long bone (tibia, femur, etc.) remodels throughout an

329 individual's life and therefore regularly uptakes new carbon, whereas the otic capsule

330 completes formation in utero and does not remodel during an individual's lifetime. Thus,

331 if a femur and otic capsule from the same individual are radiocarbon dated, two different

332 dates may be generated, particularly in advanced-age individuals. This could potentially

333 lead to discrepant date ranges for related individuals - if the otic capsule of an adult

334 female who died giving childbirth was dated, while the femur of her daughter was used,

335 there could in theory be a difference of more than 100 years. We therefore compiled data 
336 on which element of each individual was radiocarbon dated; information on which

337 skeletal element was radiocarbon dated for each individual is provided in SM 4.1.

338 Unfortunately, in many instances no information on which element was dated was

339 available in the published literature. Additionally, if information was provided, it was

340 sometimes imprecise or vague. An element might be listed as "petrous", but with no

341 information on if the otic capsule, cochlea, or ossicles were radiocarbon dated - these

342 could generate earlier dates than the surrounding petrous pyramid or temporal bone.

343 We hypothesized that there would be a higher number of individuals above the

$34454.47 \mathrm{GH}$ mean reduction for individuals in a related pair that had different skeletal

345 elements $\mathrm{C} 14$ dated. Table 4 provides counts of whether the skeletal element dated for

346 each individual was different or the same (or if no information was available) as their

347 relative. While there does seem to be a higher proportion of individuals with reductions

348 above the 54.47 year GH mean in instances where different elements were radiocarbon

349 dated, this is not statistically significant (chi-square test; $\mathrm{x}^{2}=1.96, \mathrm{p}$ value $=0.3755, \mathrm{df}=2$;

350 SM 4.4), suggesting that dating different elements of related pairs does not significantly

351 impact the reductions made with GH constraints. This likely is due to the fact that despite

352 different elements being dated, most relatives were relatively close in age (likely because

353 few individuals in pre-modern societies reached advanced age), or that the different

354 elements dated had similar bone remodeling/carbon uptake rates. Despite this, it is likely

355 that some instances of large discrepancies can be explained by the C14 dating of different

356 skeletal elements.

358 Table 4. Counts and percentage of whether the same or different skeletal elements were 359 used to date an individual in a relative pair. 


\begin{tabular}{lll}
$\begin{array}{l}\text { Comparison of } \\
\text { skeletal element } \\
\text { dated for each } \\
\text { related pair }\end{array}$ & N individuals & $\begin{array}{l}\text { \% above 54.47 } \\
\text { year mean GH } \\
\text { reduction per } \\
\text { element category }\end{array}$ \\
\hline Different elements & 26 & 50.0 \\
\hline Same element & 138 & 30.9 \\
\hline $\begin{array}{l}\text { No information } \\
\text { available }\end{array}$ & 55 & 34.1 \\
\hline
\end{tabular}

We next examined whether applying GH constraints could reveal larger patterns

364 in the dataset. To explore if there were any periods which had a higher number of

365 relatives that exceeded the mean reduction than others, we binned into 500-year intervals

366 all 3965 published individuals in the database and the 219 dated individuals with

367 genetically identified relatives. This allowed us to examine if periods with high numbers

368 of individuals above the 54.47 year mean GH reduction were indicative of anomalies in

369 the radiocarbon record (i.e. calibration curve issues, uncorrected marine reservoir effects,

370 etc) at a particular date interval, or merely an artifact of sampling the database. Figures 9a

371 and $9 \mathrm{~b}$ qualitatively demonstrate that periods with a high number of individuals with a

372 reduction above the 54.47 year mean roughly corresponds with the 500-year intervals that

373 have been most densely sampled for aDNA. We performed a $\mathrm{x}^{2}$ test to test the null

374 hypothesis that the number of individuals above the 54.47 year mean GH reductions per

375500 -year interval correlates with the total number of individuals sampled per 500-year

376 interval. We found a $\mathrm{x}^{2}$ value of $57.43(\mathrm{df}=20)$, giving a $\mathrm{p}$ value= $1.76717 \mathrm{E}-05(\mathrm{SM} 4.5)$,

377 rejecting the null hypothesis and suggesting that the number of individuals above the

37854.47 mean GH reduction per 500-year interval is not simply due to the overall number

379 of individuals sampled per 500-year interval. The most notable intervals were 7999-7500 
381 values of 4.86, 5.07, 11.59, and 1.65, respectively (SM 4.5).

382

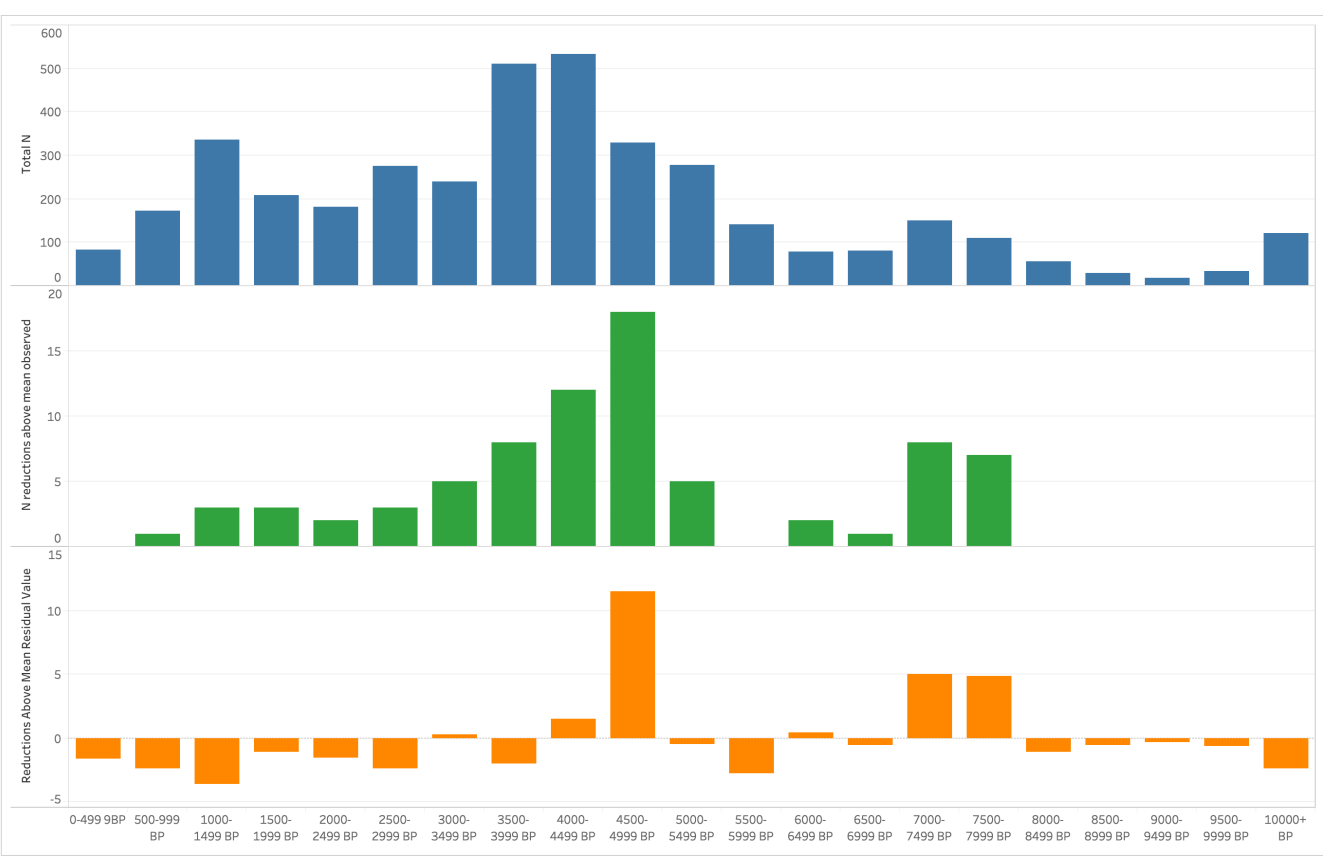

385 Figure 9. Data from the database and 219 individuals with relatives binned in 500-year intervals. A) \#of individuals total in each 500-year interval. B) \# of relatives per interval that exceed the 54.47-year mean GH reduction C) Residuals from $\mathrm{x}^{2}$ test. the 54.47-year mean $(\mathrm{n}=18)$ was $4999-4500$ calBP. The plotted radiocarbon distributions

391 of these individuals demonstrate that plateaus along the radiocarbon curve during this

392 period of time could account for the high number of reductions (Figs 10), which is also

393 true for the other three 500-year intervals with the highest $\mathrm{x}^{2}$ residual values (Figs 11-13).

394 Individuals MX188 and MX190, $1^{\text {st }}$ degree relatives from Spreitenbach,

395 Switzerland (Furtwangler et al. 2020), demonstrate how knowing genetic relatedness and 396 applying GH constraints can reduce date ranges and help correct for radiocarbon 
397 plateaus. MX 190's 2-sigma range falls on a curve plateau and is much larger than MX

398 188's (Figure 14; 2861-2342 calBCE, ETH-19935 and 2495-2399 calBCE, BE-7995.1.1,

399 respectively). However, because these individuals are known to be $1^{\text {st }}$ degree relatives the

40029 year GH constraint could be applied, reducing MX 190's range by 365 years (to 2524-

4012370 calBCE, SM 4.1).

402

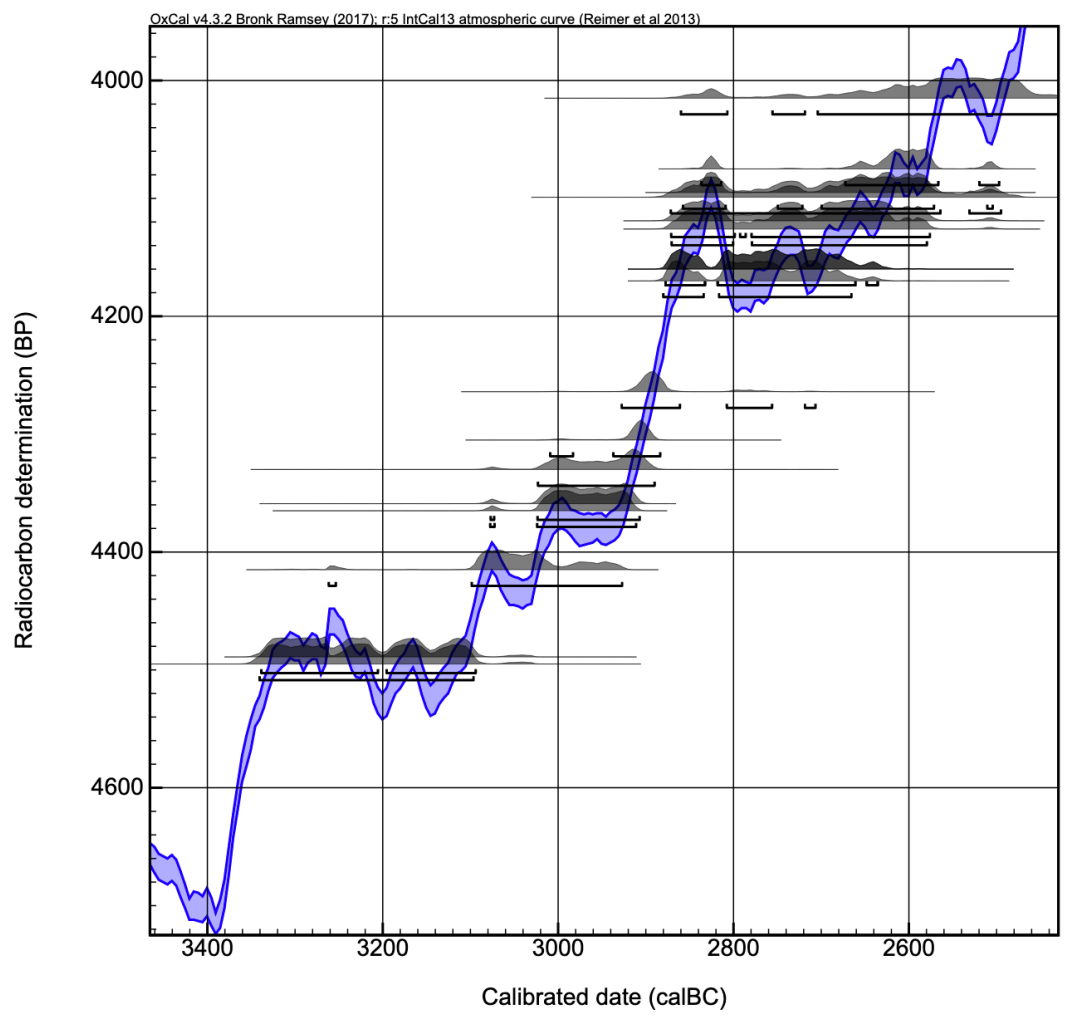

403

404 Figure 10. Original 2-sigma calBCE date ranges for individuals from the 4500-4999 405 calBP interval that had GH reductions about the 54.47 mean.

406 


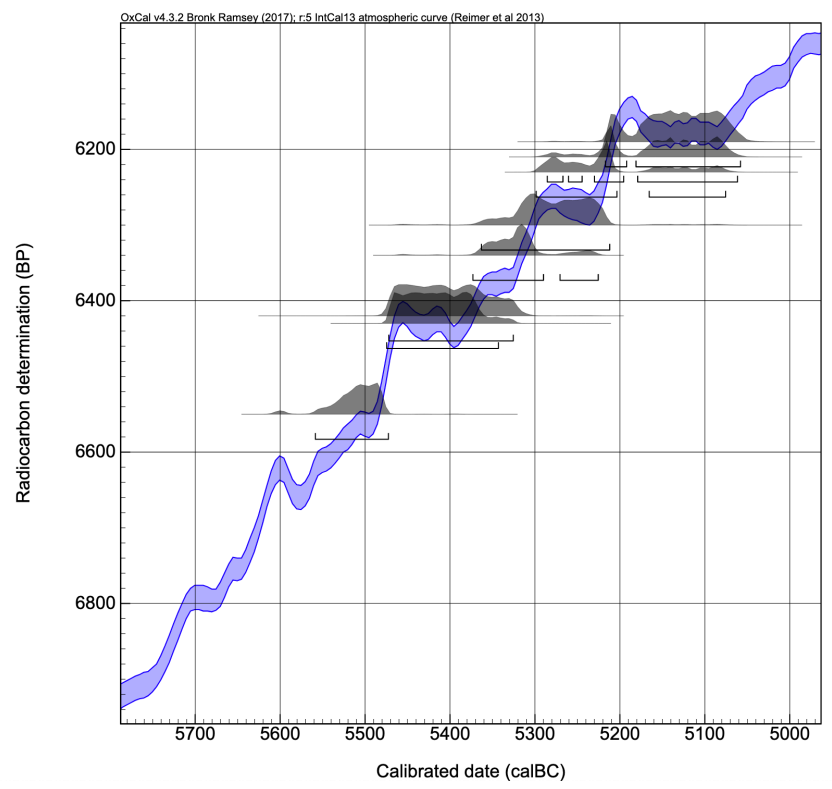

408 Figure 11. Original 2-sigma calBCE date ranges for individuals from the 7499-7000 409 calBP interval that had GH reductions about the 54.47 mean.

410

411

412

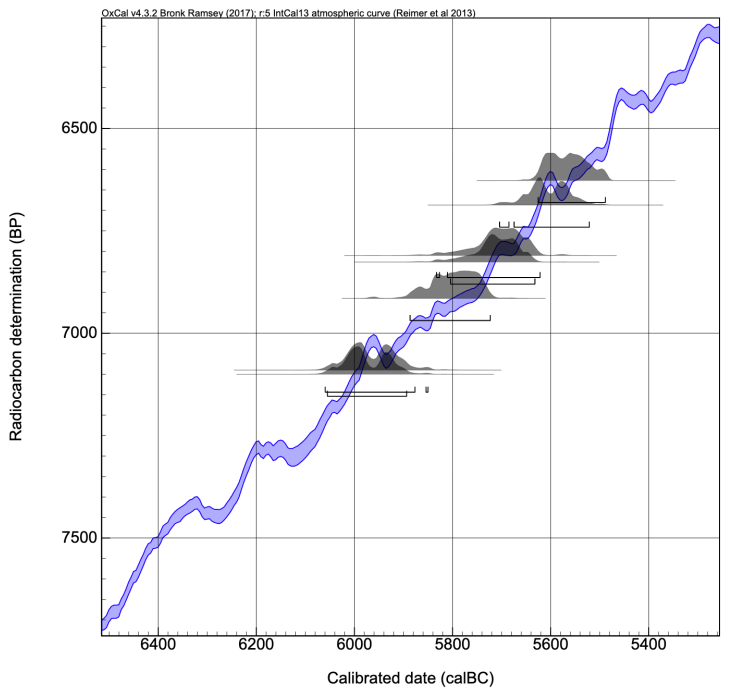

413 Figure 12. Original 2-sigma calBCE date ranges for individuals from the 7500-7999 414 calBP interval that had GH reductions about the 54.47 mean.

415 


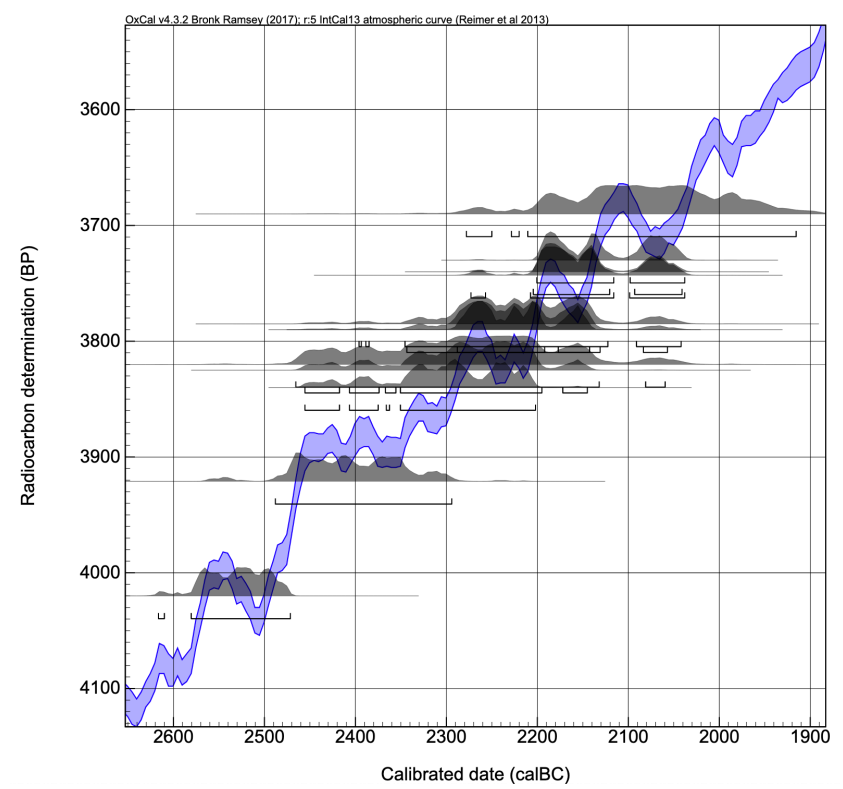

417 Figure 13. Original 2-sigma calBCE date ranges for individuals from the 4000-4499 BP 418 calBP interval that had GH reductions about the 54.47 mean.

419

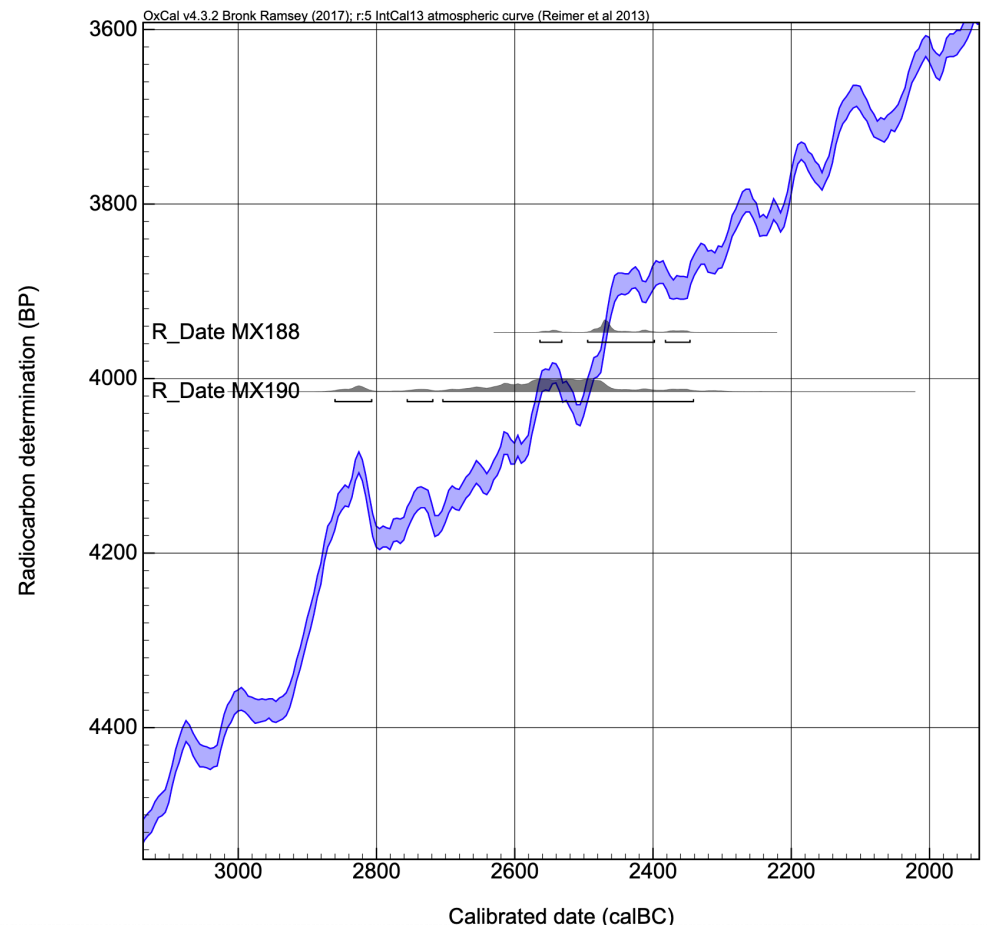

420

421 Figure 14. Original 2-sigma calBCE date ranges for MX 188 and MX 190. 
425 The range tightening described above is a "manual" method for constraining the tail ends

426 of radiocarbon date distributions using estimates for the number of years that can separate

427 the dates of death of genetic relatives. While date ranges can be constrained with this

428 manual method, we also tested how other statistical modeling could refine the date

429 ranges. Bayesian analysis to increase precision in a series of radiocarbon dates has

430 become standard practice amongst archaeologists (Bronk Ramsey, 2009; Taylor and Bar-

431 Yosef, 2014). Thus, we examined how effective knowledge of genetic relatedness and

432 date of death estimates are as priors to refine radiocarbon dates.

433 To test this, we started by importing the raw calibrated date probability

434 distributions for I2600 and I2457 from OxCal 4.3 (data provided in SM 5). We next

435 sorted the GH DOD values into 5-year intervals and produced a probability distribution.

436 The raw data were smoothed to give estimates of DOD by year (SM 5). The posterior

437 joint distribution of the datasets was then computed. Figures 15 and 16 are the marginal

438 estimates of these distributions for the father and daughter. Due to a plateau in the

439 radiocarbon curve, the date distributions for the father and daughter are bimodal with an

440 additional, lower probability "peak" (demonstrated with the purple curve). For each,

441 building in the relative information significantly reduces the probability of one of the

442 original probability peaks. And while the distribution for I2600 essentially remains

443 bimodal, the most likely probability for both I2600 and I2457 is between 2100-2000

444 BCE. This result demonstrates that building the constraints in to statistical modeling can

445 help refine date ranges. Future work building these constraints into Bayesian modeling

446 available in OxCal could provide additional refinements. 


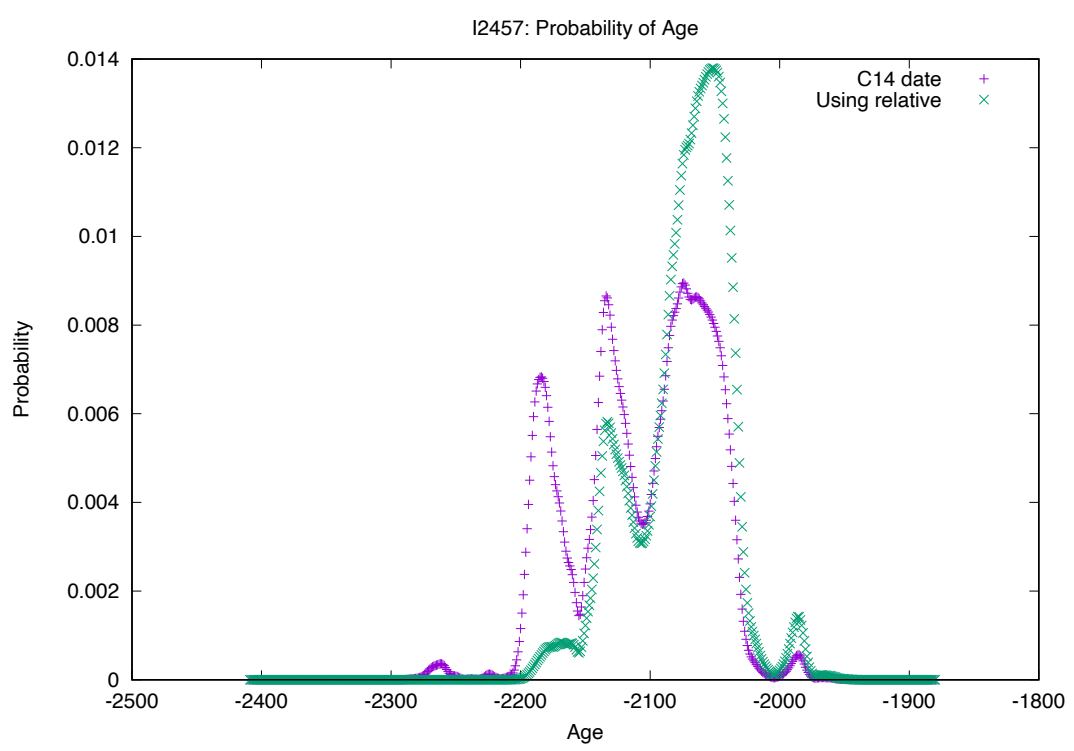

448

449 Figure 15. Joint probability distribution for I2457. Original AMS date probability 450 distribution in purple, new joint distribution in green.

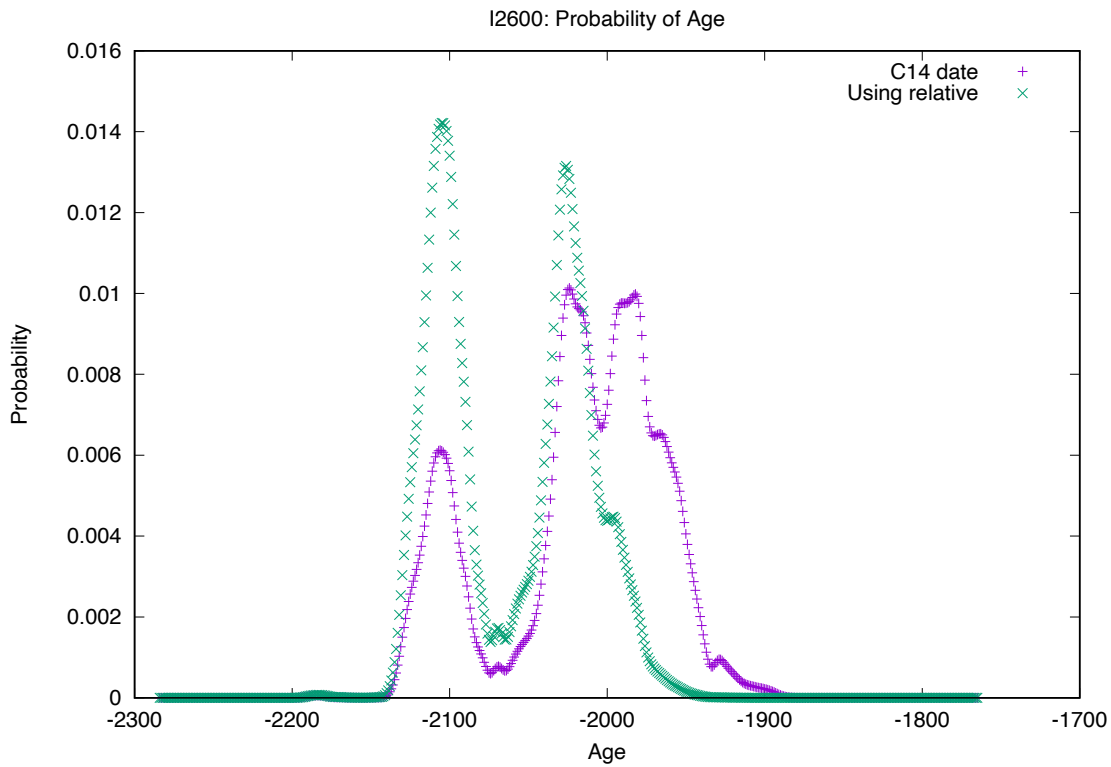

452 Figure 16. Joint probability distribution for I2600. Original AMS date probability 453 distribution in purple, new joint distribution in green.

454 
457 In sum, knowledge of genetic relatedness can be used to constrain radiocarbon date

458 distributions, either by applying DOD separations to the tail ends of the distributions, or

459 through Bayesian modeling. These refinements are not universally applicable; related

460 pairs often have date distributions that overlap, sometimes almost entirely, limiting the

461 extent to which DOD estimates can refine date ranges. Yet, overlap is what should be

462 expected; related individuals should not have large date separations. Date distributions of

463 related individuals that do not overlap could reveal an error in radiocarbon dating (such

464 as I2600 and I2457) or genetic analysis, or other issues, such as an uncorrected marine

465 reservoir effect. In other words, the more substantially DOD separation estimates can

466 constrain $\mathrm{C} 14$ date ranges, the more likely a significant issue exists in dating for any of a

467 variety of reasons (unaccounted marine reservoir effect, curve plateau, etc).

470 4. Discussion

472 Combining previously independent lines of data - knowledge of genetic relatedness

473 derived from ancient DNA; biological and estimated DOD separations for relatives; and

474 radiocarbon dates - creates potential benefits for researchers examining the ancient past.

475 Perhaps the most apparent is evaluation of data generated through disparate methods. As

476 discussed above, relatedness often confirms radiocarbon dates (and vice-versa, Saag et

477 al., 2019:5). Using genetic relatedness and DOD separation estimates to evaluate

478 radiocarbon dates can also help attend to some of the most common pitfalls in

479 radiocarbon dating. According to Taylor and Bar-Yosef (2014:132), "the most common 
480 reason why $\mathrm{C} 14$ dating evidence is considered to be anomalous can be traced to failures

481 to clearly establish and document the physical relationship between a C14 dated sample

482 and a specific targeted event or cultural expression." Somewhat counterintuitively,

483 incorporating genetic relationship DOD-separations addresses Taylor and Bar-Yosef's

484 concerns by circumventing taphonomic processes. Instead of focusing on potential

485 confounding factors of when individuals were buried, removed, reburied, etc., date ranges

486 are examined with an independent line of evidence that is not prone to contamination

487 issues associated with taphonomic processes and archaeological context.

488 Analyzing the radiocarbon record with knowledge of genetic relatives also

489 provides archaeologists an opportunity to move beyond traditional interpretations of

490 radiocarbon dates. C14 dating of skeletal remains typically provides an estimate of when

491 an individual died (although it could also reflect when a particular element ceased carbon

492 uptake during an individual's lifetime, as discussed above). The combined and

493 constrained date ranges discussed above provide minimum and maximum boundaries of

494 when two related individuals died; therefore, the overlap of the two ranges likely contains

495 the plausible period of time when the individuals were alive together. It is entirely

496 possible, of course, that one individual died at the minimum boundary and the other at the

497 maximum. In such instances the two related individuals would have no lifetime overlap.

498 Even in such cases, considering the combined C14 ranges of related individuals can turn

499 archaeological thinking away from incipient or terminal dates of archaeological periods,

500 but instead toward changes that happened during lifetimes.

501 Considering lifespan ranges also helps elucidate cultural plasticity, and reveal the

502 arbitrariness of archaeological boundaries. Archaeologists had initially suspected the 
503 English Bell Beaker father-daughter pair were part of separate archaeological cultures

504 due to their initial dates. Knowing that these two individuals were related not only helped

505 in identifying an error in the initial radiocarbon dates, but also speaks to the subjective

506 nature of chronological and cultural boundaries archaeologists establish, which were of

507 no consequence for the father-daughter pair.

508 The approaches outlined above represent only a small number of applications for

509 how knowledge of genetic relatedness can help with radiocarbon dating. The potential for

510 further applicability needs to be explored; one promising application could be the use of

511 extended families for radiocarbon curve "wiggle matching."

512

513

514 5. Conclusion

515

516 This research is a first step in combining two discrete analytical methods to add

517 refinement to interpretation of the archaeological record and is meant to demonstrate that

518 knowledge of genetic relatedness can be used to augment radiocarbon dating. As ancient

519 DNA databases continue to grow, and more relatives are identified and radiocarbon

520 dated, researchers will likely feel compelled to refine GH and DOD estimates as they see

521 fit, as some have already done (Kennett et al., 2017; Saag et al., 2019). Levels of social

522 organization (e.g. hunter-gatherer vs. agriculturalist), age of skeletons (adult vs. juvenile),

523 and lifespan estimate could also all be incorporated into estimates. Additionally, once

524 enough related individuals are identified and dated, specific regions, sub-regions, or even

525 sites can be examined for anomalies in the associated radiocarbon records. 
527 insight into the past. As ancient DNA becomes increasingly integral to archaeological

528 studies, researchers should explore novel applications of genetic data to archaeological

529 studies. This paper used ancient DNA to identify radiocarbon outliers, refine date

530 distribution ranges for related pairs, and delineate potential issues unaccounted for in the

531 radiocarbon record of particular eras and locales. Such studies should help integrate the

532 two fields and move ancient DNA and archaeology forward together into the next era of

533 research on the human past.

534

\section{Declaration of Competing Interests}

536 None

\section{Acknowledgements}

539 This work was funded by NIH grant GM100233, the Paul Allen Foundation, John

540 Templeton Foundation (grant number 6122), and David Reich is an Investigator of the

541 Howard Hughes Medical Institute. We thank Melissa Gymrek for providing assistance

542 with familinx data from the Kaplanis et al. 2018 study, Greg Hodgins for reviewing an

543 early draft of the paper, Iain Mathieson and Vagheesh Narasimhan for statistical

544 assistance, and members of our laboratory for feedback on the study during its

545 development.

546

547

548

549

550

551 


\section{References Cited}

Bronk Ramsey, C., 2009. Bayesian Analysis of Radiocarbon Dates. Radiocarbon 51, 337-360. https://doi.org/10.1017/S0033822200033865

Calcagnile, L., Quarta, G., Cattaneo, C., D'Elia, M., 2013. Determining ${ }^{14}$ C Content in Different Human Tissues: Implications for Application of ${ }^{14} \mathrm{C}$ Bomb-Spike Dating in Forensic Medicine. Radiocarbon 55, 1845-1849. https://doi.org/10.1017/S003382220004875X

Cook, G.T., Ainscough, L.A.N., Dunbar, E., 2015. Radiocarbon Analysis of Modern Skeletal Remains to Determine Year of Birth and Death - A Case Study. Radiocarbon 57, 327-336. https://doi.org/10.2458/azu_rc.57.18394

Hansen, H.B., Damgaard, P.B., Margaryan, A., Stenderup, J., Lynnerup, N., Willerslev, E., Allentoft, M.E., 2017. Comparing Ancient DNA Preservation in Petrous Bone and Tooth Cementum. PLOS ONE 12, e0170940. https://doi.org/10.1371/journal.pone.0170940

Kaplanis, J., Gordon, A., Shor, T., Weissbrod, O., Geiger, D., Wahl, M., Gershovits, M., Markus, B., Sheikh, M., Gymrek, M., Bhatia, G., MacArthur, D.G., Price, A.L., Erlich, Y., 2018. Quantitative analysis of population-scale family trees with millions of relatives. Science 360, 171-175. https://doi.org/10.1126/science.aam9309

Kennett, D.J., Plog, S., George, R.J., Culleton, B.J., Watson, A.S., Skoglund, P., Rohland, N., Mallick, S., Stewardson, K., Kistler, L., LeBlanc, S.A., Whiteley, P.M., Reich, D., Perry, G.H., 2017. Archaeogenomic evidence reveals prehistoric matrilineal dynasty. Nature Communications 8, 14115. https://doi.org/10.1038/ncomms14115

Kuhn, J.M.M., Jakobsson, M., Günther, T., 2018. Estimating genetic kin relationships in prehistoric populations. PLOS ONE 13, e0195491. https://doi.org/10.1371/journal.pone.0195491

Lazaridis, I., Nadel, D., Rollefson, G., Merrett, D.C., Rohland, N., Mallick, S., Fernandes, D., Novak, M., Gamarra, B., Sirak, K., Connell, S., Stewardson, K., Harney, E., Fu, Q., Gonzalez-Fortes, G., Jones, E.R., Roodenberg, S.A., Lengyel, G., Bocquentin, F., Gasparian, B., Monge, J.M., Gregg, M., Eshed, V., Mizrahi, A.-S., Meiklejohn, C., Gerritsen, F., Bejenaru, L., Blüher, M., Campbell, A., Cavalleri, G., Comas, D., Froguel, P., Gilbert, E., Kerr, S.M., Kovacs, P., Krause, J., McGettigan, D., Merrigan, M., Merriwether, D.A., O'Reilly, S., Richards, M.B., Semino, O., Shamoon-Pour, M., Stefanescu, G., Stumvoll, M., Tönjes, A., Torroni, A., Wilson, J.F., Yengo, L., Hovhannisyan, N.A., Patterson, N., Pinhasi, R., Reich, D., 2016. Genomic insights into the origin of farming in the ancient Near East. Nature 536, 419-424. https://doi.org/10.1038/nature19310

Lipson, M., Skoglund, P., Spriggs, M., Valentin, F., Bedford, S., Shing, R., Buckley, H., Phillip, I., Ward, G.K., Mallick, S., Rohland, N., Broomandkhoshbacht, N., Cheronet, O., Ferry, M., Harper, T.K., Michel, M., Oppenheimer, J., Sirak, K., Stewardson, K., Auckland, K., Hill, A.V.S., Maitland, K., Oppenheimer, S.J., Parks, T., Robson, K., Williams, T.N., Kennett, D.J., Mentzer, A.J., Pinhasi, R., 
Reich, D., 2018. Population Turnover in Remote Oceania Shortly after Initial Settlement. Current Biology 28, 1157-1165.e7. https://doi.org/10.1016/j.cub.2018.02.051

Marciniak, S., Perry, G.H., 2017. Harnessing ancient genomes to study the history of human adaptation. Nature Reviews Genetics 18, 659-674. https://doi.org/10.1038/nrg.2017.65

Mathieson, I., Lazaridis, I., Rohland, N., Mallick, S., Patterson, N., Roodenberg, S.A., Harney, E., Stewardson, K., Fernandes, D., Novak, M., Sirak, K., Gamba, C., Jones, E.R., Llamas, B., Dryomov, S., Pickrell, J., Arsuaga, J.L., de Castro, J.M.B., Carbonell, E., Gerritsen, F., Khokhlov, A., Kuznetsov, P., Lozano, M., Meller, H., Mochalov, O., Moiseyev, V., Guerra, M.A.R., Roodenberg, J., Vergès, J.M., Krause, J., Cooper, A., Alt, K.W., Brown, D., Anthony, D., Lalueza-Fox, C., Haak, W., Pinhasi, R., Reich, D., 2015. Genome-wide patterns of selection in 230 ancient Eurasians. Nature 528, 499-503. https://doi.org/10.1038/nature 16152

Moreno-Mayar, J.V., Vinner, L., de Barros Damgaard, P., de la Fuente, C., Chan, J., Spence, J.P., Allentoft, M.E., Vimala, T., Racimo, F., Pinotti, T., Rasmussen, S., Margaryan, A., Iraeta Orbegozo, M., Mylopotamitaki, D., Wooller, M., Bataille, C., Becerra-Valdivia, L., Chivall, D., Comeskey, D., Devièse, T., Grayson, D.K., George, L., Harry, H., Alexandersen, V., Primeau, C., Erlandson, J., RodriguesCarvalho, C., Reis, S., Bastos, M.Q.R., Cybulski, J., Vullo, C., Morello, F., Vilar, M., Wells, S., Gregersen, K., Hansen, K.L., Lynnerup, N., Mirazón Lahr, M., Kjær, K., Strauss, A., Alfonso-Durruty, M., Salas, A., Schroeder, H., Higham, T., Malhi, R.S., Rasic, J.T., Souza, L., Santos, F.R., Malaspinas, A.-S., Sikora, M., Nielsen, R., Song, Y.S., Meltzer, D.J., Willerslev, E., 2018. Early human dispersals within the Americas. Science 362, eaav2621. https://doi.org/10.1126/science.aav2621

Narasimhan, V.M., Patterson, N., Moorjani, P., Rohland, N., Bernardos, R., Mallick, S., Lazaridis, I., Nakatsuka, N., Olalde, I., Lipson, M., Kim, A.M., Olivieri, L.M., Coppa, A., Vidale, M., Mallory, J., Moiseyev, V., Kitov, E., Monge, J., Adamski, N., Alex, N., Broomandkhoshbacht, N., Candilio, F., Callan, K., Cheronet, O., Culleton, B.J., Ferry, M., Fernandes, D., Freilich, S., Gamarra, B., Gaudio, D., Hajdinjak, M., Harney, É., Harper, T.K., Keating, D., Lawson, A.M., Mah, M., Mandl, K., Michel, M., Novak, M., Oppenheimer, J., Rai, N., Sirak, K., Slon, V., Stewardson, K., Zalzala, F., Zhang, Z., Akhatov, G., Bagashev, A.N., Bagnera, A., Baitanayev, B., Bendezu-Sarmiento, J., Bissembaev, A.A., Bonora, G.L., Chargynov, T.T., Chikisheva, T., Dashkovskiy, P.K., Derevianko, A., Dobeš, M., Douka, K., Dubova, N., Duisengali, M.N., Enshin, D., Epimakhov, A., Fribus, A.V., Fuller, D., Goryachev, A., Gromov, A., Grushin, S.P., Hanks, B., Judd, M., Kazizov, E., Khokhlov, A., Krygin, A.P., Kupriyanova, E., Kuznetsov, P., Luiselli, D., Maksudov, F., Mamedov, A.M., Mamirov, T.B., Meiklejohn, C., Merrett, D.C., Micheli, R., Mochalov, O., Mustafokulov, S., Nayak, A., Pettener, D., Potts, R., Razhev, D., Rykun, M., Sarno, S., Savenkova, T.M., Sikhymbaeva, K., Slepchenko, S.M., Soltobaev, O.A., Stepanova, N., Svyatko, S., Tabaldiev, K., Teschler-Nicola, M., Tishkin, A.A., Tkachev, V.V., Vasilyev, S., Velemínský, P., Voyakin, D., Yermolayeva, A., Zahir, M., Zubkov, V.S., Zubova, A., Shinde, V.S., Lalueza-Fox, C., Meyer, M., Anthony, D., Boivin, N., Thangaraj, K., 
644

645

646

647

648

649

650

651

652

653

654

655

656

657

658

659

660

661

662

663

664

665

666

667

668

669

670

671

672

673

674

675

676

677

678

679

680

681

682

683

684

685

686

687

688

689

Kennett, D.J., Frachetti, M., Pinhasi, R., Reich, D., 2019. The formation of human populations in South and Central Asia. Science 365, eaat7487.

https://doi.org/10.1126/science.aat7487

Olalde, I., Brace, S., Allentoft, M.E., Armit, I., Kristiansen, K., Booth, T., Rohland, N., Mallick, S., Szécsényi-Nagy, A., Mittnik, A., Altena, E., Lipson, M., Lazaridis, I., Harper, T.K., Patterson, N., Broomandkhoshbacht, N., Diekmann, Y., Faltyskova, Z., Fernandes, D., Ferry, M., Harney, E., de Knijff, P., Michel, M., Oppenheimer, J., Stewardson, K., Barclay, A., Alt, K.W., Liesau, C., Ríos, P., Blasco, C., Miguel, J.V., García, R.M., Fernández, A.A., Bánffy, E., Bernabò-Brea, M., Billoin, D., Bonsall, C., Bonsall, L., Allen, T., Büster, L., Carver, S., Navarro, L.C., Craig, O.E., Cook, G.T., Cunliffe, B., Denaire, A., Dinwiddy, K.E., Dodwell, N., Ernée, M., Evans, C., Kuchařík, M., Farré, J.F., Fowler, C., Gazenbeek, M., Pena, R.G., Haber-Uriarte, M., Haduch, E., Hey, G., Jowett, N., Knowles, T., Massy, K., Pfrengle, S., Lefranc, P., Lemercier, O., Lefebvre, A., Martínez, C.H., Olmo, V.G., Ramírez, A.B., Maurandi, J.L., Majó, T., McKinley, J.I., McSweeney, K., Mende, B.G., Mod, A., Kulcsár, G., Kiss, V., Czene, A., Patay, R., Endrödi, A., Köhler, K., Hajdu, T., Szeniczey, T., Dani, J., Bernert, Z., Hoole, M., Cheronet, O., Keating, D., Velemínský, P., Dobeš, M., Candilio, F., Brown, F., Fernández, R.F., Herrero-Corral, A.-M., Tusa, S., Carnieri, E., Lentini, L., Valenti, A., Zanini, A., Waddington, C., Delibes, G., Guerra-Doce, E., Neil, B., Brittain, M., Luke, M., Mortimer, R., Desideri, J., Besse, M., Brücken, G., Furmanek, M., Hałuszko, A., Mackiewicz, M., Rapiński, A., Leach, S., Soriano, I., Lillios, K.T., Cardoso, J.L., Pearson, M.P., Włodarczak, P., Price, T.D., Prieto, P., Rey, P.-J., Risch, R., Rojo Guerra, M.A., Schmitt, A., Serralongue, J., Silva, A.M., Smrčka, V., Vergnaud, L., Zilhão, J., Caramelli, D., Higham, T., Thomas, M.G., Kennett, D.J., Fokkens, H., Heyd, V., Sheridan, A., Sjögren, K.-G., Stockhammer, P.W., Krause, J., Pinhasi, R., Haak, W., Barnes, I., Lalueza-Fox, C., Reich, D., 2018. The Beaker phenomenon and the genomic transformation of northwest Europe. Nature 555, 190-196. https://doi.org/10.1038/nature25738

Olalde, I., Mallick, S., Patterson, N., Rohland, N., Villalba-Mouco, V., Silva, M., Dulias, K., Edwards, C.J., Gandini, F., Pala, M., Soares, P., Ferrando-Bernal, M., Adamski, N., Broomandkhoshbacht, N., Cheronet, O., Culleton, B.J., Fernandes, D., Lawson, A.M., Mah, M., Oppenheimer, J., Stewardson, K., Zhang, Z., Jiménez Arenas, J.M., Toro Moyano, I.J., Salazar-García, D.C., Castanyer, P., Santos, M., Tremoleda, J., Lozano, M., García Borja, P., Fernández-Eraso, J., Mujika-Alustiza, J.A., Barroso, C., Bermúdez, F.J., Viguera Mínguez, E., Burch, J., Coromina, N., Vivó, D., Cebrià, A., Fullola, J.M., García-Puchol, O., Morales, J.I., Oms, F.X., Majó, T., Vergès, J.M., Díaz-Carvajal, A., Ollich-Castanyer, I., López-Cachero, F.J., Silva, A.M., Alonso-Fernández, C., Delibes de Castro, G., Jiménez Echevarría, J., Moreno-Márquez, A., Pascual Berlanga, G., RamosGarcía, P., Ramos-Muñoz, J., Vijande Vila, E., Aguilella Arzo, G., Esparza Arroyo, Á., Lillios, K.T., Mack, J., Velasco-Vázquez, J., Waterman, A., Benítez de Lugo Enrich, L., Benito Sánchez, M., Agustí, B., Codina, F., de Prado, G., Estalrrich, A., Fernández Flores, Á., Finlayson, C., Finlayson, G., Finlayson, S., Giles-Guzmán, F., Rosas, A., Barciela González, V., García Atiénzar, G., Hernández Pérez, M.S., Llanos, A., Carrión Marco, Y., Collado Beneyto, I., 
López-Serrano, D., Sanz Tormo, M., Valera, A.C., Blasco, C., Liesau, C., Ríos, P., Daura, J., de Pedro Michó, M.J., Diez-Castillo, A.A., Flores Fernández, R., Francès Farré, J., Garrido-Pena, R., Gonçalves, V.S., Guerra-Doce, E., HerreroCorral, A.M., Juan-Cabanilles, J., López-Reyes, D., McClure, S.B., Merino Pérez, M., Oliver Foix, A., Sanz Borràs, M., Sousa, A.C., Vidal Encinas, J.M., Kennett, D.J., Richards, M.B., Werner Alt, K., Haak, W., Pinhasi, R., Lalueza-Fox, C., Reich, D., 2019. The genomic history of the Iberian Peninsula over the past 8000 years. Science 363, 1230-1234. https://doi.org/10.1126/science.aav4040

Pinhasi, R., Fernandes, D., Sirak, K., Novak, M., Connell, S., Alpaslan-Roodenberg, S., Gerritsen, F., Moiseyev, V., Gromov, A., Raczky, P., Anders, A., Pietrusewsky, M., Rollefson, G., Jovanovic, M., Trinhhoang, H., Bar-Oz, G., Oxenham, M., Matsumura, H., Hofreiter, M., 2015. Optimal Ancient DNA Yields from the Inner Ear Part of the Human Petrous Bone. PLOS ONE 10, e0129102. https://doi.org/10.1371/journal.pone.0129102

Posth, C., Nakatsuka, N., Lazaridis, I., Skoglund, P., Mallick, S., Lamnidis, T.C., Rohland, N., Nägele, K., Adamski, N., Bertolini, E., Broomandkhoshbacht, N., Cooper, A., Culleton, B.J., Ferraz, T., Ferry, M., Furtwängler, A., Haak, W., Harkins, K., Harper, T.K., Hünemeier, T., Lawson, A.M., Llamas, B., Michel, M., Nelson, E., Oppenheimer, J., Patterson, N., Schiffels, S., Sedig, J., Stewardson, K., Talamo, S., Wang, C.-C., Hublin, J.-J., Hubbe, M., Harvati, K., Nuevo Delaunay, A., Beier, J., Francken, M., Kaulicke, P., Reyes-Centeno, H., Rademaker, K., Trask, W.R., Robinson, M., Gutierrez, S.M., Prufer, K.M., Salazar-García, D.C., Chim, E.N., Müller Plumm Gomes, L., Alves, M.L., Liryo, A., Inglez, M., Oliveira, R.E., Bernardo, D.V., Barioni, A., Wesolowski, V., Scheifler, N.A., Rivera, M.A., Plens, C.R., Messineo, P.G., Figuti, L., Corach, D., Scabuzzo, C., Eggers, S., DeBlasis, P., Reindel, M., Méndez, C., Politis, G., Tomasto-Cagigao, E., Kennett, D.J., Strauss, A., Fehren-Schmitz, L., Krause, J., Reich, D., 2018. Reconstructing the Deep Population History of Central and South America. Cell 175, 1185-1197.e22. https://doi.org/10.1016/j.cell.2018.10.027

Rasmussen, M., Anzick, S.L., Waters, M.R., Skoglund, P., DeGiorgio, M., Stafford, T.W., Rasmussen, S., Moltke, I., Albrechtsen, A., Doyle, S.M., Poznik, G.D., Gudmundsdottir, V., Yadav, R., Malaspinas, A.-S., V, S.S.W., Allentoft, M.E., Cornejo, O.E., Tambets, K., Eriksson, A., Heintzman, P.D., Karmin, M., Korneliussen, T.S., Meltzer, D.J., Pierre, T.L., Stenderup, J., Saag, L., Warmuth, V.M., Lopes, M.C., Malhi, R.S., Brunak, S., Sicheritz-Ponten, T., Barnes, I., Collins, M., Orlando, L., Balloux, F., Manica, A., Gupta, R., Metspalu, M., Bustamante, C.D., Jakobsson, M., Nielsen, R., Willerslev, E., 2014. The genome of a Late Pleistocene human from a Clovis burial site in western Montana. Nature 506, 225-229. https://doi.org/10.1038/nature13025

Reich, D., 2018. Who We Are and How We Got Here: Ancient DNA and the New Science of the Human Past. Pantheon, New York.

Reich, D., Green, R.E., Kircher, M., Krause, J., Patterson, N., Durand, E.Y., Viola, B., Briggs, A.W., Stenzel, U., Johnson, P.L.F., Maricic, T., Good, J.M., MarquesBonet, T., Alkan, C., Fu, Q., Mallick, S., Li, H., Meyer, M., Eichler, E.E., Stoneking, M., Richards, M., Talamo, S., Shunkov, M.V., Derevianko, A.P., 
762

763

Hublin, J.-J., Kelso, J., Slatkin, M., Pääbo, S., 2010. Genetic history of an archaic hominin group from Denisova Cave in Siberia. Nature 468, 1053-1060. https://doi.org/10.1038/nature09710

Saag, Lehti, Laneman, M., Varul, L., Malve, M., Valk, H., Razzak, M.A., Shirobokov, I.G., Khartanovich, V.I., Mikhaylova, E.R., Kushniarevich, A., Scheib, C.L., Solnik, A., Reisberg, T., Parik, J., Saag, Lauri, Metspalu, E., Rootsi, S., Montinaro, F., Remm, M., Mägi, R., D’Atanasio, E., Crema, E.R., Díez-delMolino, D., Thomas, M.G., Kriiska, A., Kivisild, T., Villems, R., Lang, V., Metspalu, M., Tambets, K., 2019. The Arrival of Siberian Ancestry Connecting the Eastern Baltic to Uralic Speakers further East. Current Biology S0960982219304245. https://doi.org/10.1016/j.cub.2019.04.026

Skoglund, P., Posth, C., Sirak, K., Spriggs, M., Valentin, F., Bedford, S., Clark, G.R., Reepmeyer, C., Petchey, F., Fernandes, D., Fu, Q., Harney, E., Lipson, M., Mallick, S., Novak, M., Rohland, N., Stewardson, K., Abdullah, S., Cox, M.P., Friedlaender, F.R., Friedlaender, J.S., Kivisild, T., Koki, G., Kusuma, P., Merriwether, D.A., Ricaut, F.-X., Wee, J.T.S., Patterson, N., Krause, J., Pinhasi, R., Reich, D., 2016. Genomic insights into the peopling of the Southwest Pacific. Nature 538, 510-513. https://doi.org/10.1038/nature19844

Taylor, R.E., Bar-Yosef, O., 2014. Radiocarbon dating: an archaeological perspective, Second edition. ed. Left Coast Press, Inc, Walnut Creek, California.

van de Loosdrecht, M., Bouzouggar, A., Humphrey, L., Posth, C., Barton, N., AximuPetri, A., Nickel, B., Nagel, S., Talbi, E.H., El Hajraoui, M.A., Amzazi, S., Hublin, J.-J., Pääbo, S., Schiffels, S., Meyer, M., Haak, W., Jeong, C., Krause, J., 2018. Pleistocene North African genomes link Near Eastern and sub-Saharan African human populations. Science 360, 548-552. https://doi.org/10.1126/science.aar8380 